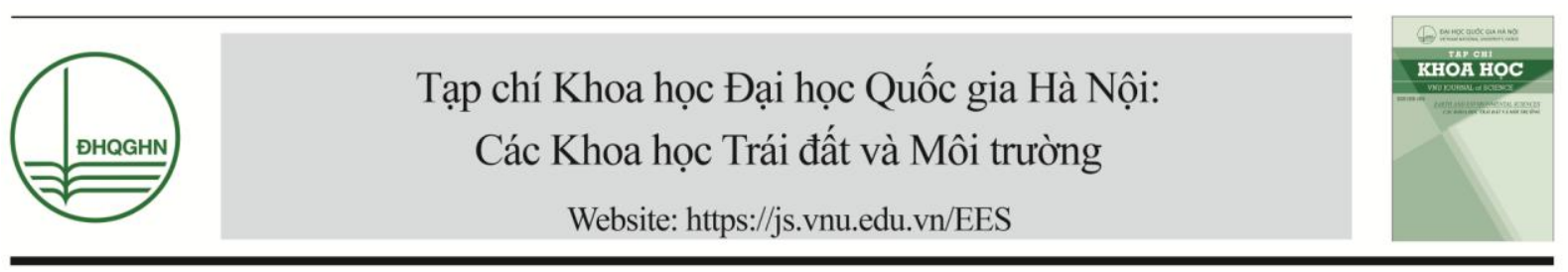

\title{
Đánh giá mức độ phân bố và tích lũy của polybrom diphenyl ete trong trầm tích tại làng nghề tái chế nhựa Minh Khai, thị trấn Như Quỳnh, tỉnh Hưng Yên
}

\author{
Trịnh Thị Thắm ${ }^{1, *}$, Nguyễn Thị Hường ${ }^{2}$, Bùi Thị Phương ${ }^{1}$, Lê Thị Trinh ${ }^{1}$ \\ ${ }^{I}$ Trường Đại học Tài nguyên và Môi truoòng Hà Nội, 41A Phú Diên, Bắc Tù Liêm, Hà Nội, Việt Nam \\ ${ }^{2}$ Truoòng Đại học Y tế Công cộng Hà Nội, 1 A Đức Thắng, Đông Ngạc, Bắc Tù Liêm, Hà Nội, Việt Nam \\ Nhận ngày 10 tháng 4 năm 2018 \\ Chỉnh sửa ngày 18 tháng 4 năm 2018; Chấp nhận đăng ngày 19 tháng 4 năm 2018
}

\begin{abstract}
Tóm tắt: Nghiên cứu này đánh giá mức độ tích lũy của 07 đồng loại Polybrom diphenyl ethers PBDEs (BDE-28, BDE-47, BDE-100, BDE-99, BDE-154, BDE-153, BDE-183) trong trầm tích bùn và hai loại động vật nhuyễn thể sinh sống tại làng nghề tái chế nhựa Minh Khai, tỉnh Hưng Yên là trai sông (Anodonta cygnea) và ốc bươu vàng (Pomacea canaliculata). Các mẫu được chiết bằng kỹ thuật chiết Soxhlet và định lượng trên thiết bị GC/MS sử dụng phương pháp nội chuẩn. Hàm lượng tổng PBDEs trong mẫu bùn dao động trong khoảng $6,03 \div 183 \mathrm{ng} / \mathrm{g}$ trong lượng khô (dry wt) và trong mẫu nhuyễn thể là $10,2 \div 129 \mathrm{ng} / \mathrm{g}$ trọng lượng ướt (wet wt). Kết quả nghiên cứu cho thấy sự tích lũy PBDEs trong trầm tích bùn tại các khu vực nghiên cứu là khá cao, đồng thời, có mối tương quan thuận giữa hàm lượng $\mathrm{PBDEs}$ trong mẫu sinh học và mẫu trầm tích. Chỉ số BSAF cũng cho thấy mức độ tích lũy cao của PBDEs trong các sinh vật nghiên cứu tại khu vực làng nghề. Đây là cơ sở khoa học cho việc đánh giá các rủi ro sinh thái và rủi ro môi trường đối với sự ô nhiễm PBDEs trong môi trường tại làng nghề.
\end{abstract}

Từ khoá: PBDEs, BSAF, trầm tích, mức độ tích lũy.

\section{Mở đầu}

Tại nhiều làng nghề ở Việt Nam và nhất là các loại hình làng nghề tái chể kim loại, tái chế nhựa, sản xuất thủ công - mỹ nghệ, các đối tượng môi trường không khí, nước, đất đang bị

\footnotetext{
*Tác giả liên hệ. ĐT.: 84-983307385.

Email: tttham@hunre.edu.vn

https://doi.org/10.25073/2588-1140/vnunst.4243
}

ô nhiễm và tiềm ẩn nhiều nguy cơ rủi ro, ảnh hưởng đến sức khỏe con người.

Làng nghề tái chế nhựa Minh Khai thuộc thị trấn Như Quỳnh, huyện Văn Lâm, tỉnh Hưng Yên có khoảng 1000 hộ dân tham gia hoạt động tái chế nhựa trong đó có khoảng 350 hộ sản xuất hạt nhựa, 300 hộ sản xuất túi nilon, 250 hộ sản xuất nhựa PVC. Các hoạt động sản xuất, tài chế tại địa phương này còn nhỏ lẻ, sử dụng công nghệ lạc hậu và chưa có các hệ thống xử lý nước thải, khí thải hoặc có nhưng chưa đạt 
yêu cầu nên môi trường tại làng nghề bị ảnh hưởng nghiêm trọng. Theo Báo cáo kết quả công tác bảo vệ môi trường trong xây dựng nông thôn mới trên địa bàn tỉnh Hưng Yên năm 2017 (Số 413/BC-STNMT), làng nghề tái chế nhựa Minh Khai là một trong các cơ sở gây ô nhiễm môi trường nghiêm trọng cần được xử lý triệt để trên địa bàn tỉnh. Năm 2016, Ủy ban nhân dân tỉnh Hưng Yên đã xây dựng khu công nghiệp sản xuất tập trung với diện tích 10 ha và có hệ thống xử lý với công suất $500 \mathrm{~m}^{3} /$ ngày đêm trên địa bàn xã. Song thực tế khảo sát của nghiên cứu cho thấy, đa phần các cơ sở sản xuất chưa di dời ra khu công nghiệp mà vẫn nằm trong khu dân cư, nước thải sản xuất xả trực tiếp ra các ao hồ trong làng và chất thải nhựa phế liệu tập kết tại các khu vực quanh làng. Hiện trạng này đã gây sức ép lên môi trường tại địa phương, đặc biệt là các nguồn thải kể trên chứa nhiều hóa chất nguy hại trong đó có các hợp chất hữu cơ bền vững.

PBDEs là nhóm các hợp chất hữu cơ gây ô nhiễm bền vững được bổ sung vào Công ước Stockholm năm 2009 vì đây là nhóm chất hữu cơ dẫn xuất halogen có độc tính cao, bền bững trong môi trường và có khả năng tích lũy sinh học. Các PBDEs phát sinh từ các hoạt động thương mại liên quan đến ngành nhựa, đồ gia dụng, cao su... chúng phát tán vào môi trường từ nước thải, chất thải rắn, tích tụ trong các hạt rắn lơ lửng và lắng đọng lại trong trầm tích [1].

Hiện nay, Cơ quan Nghiên cứu về ung thư Quốc tế (International Agency for Research on Cancer - IARC) chưa xếp PBDEs vào nhóm chất gây ung thư. Tuy nhiên, một số nghiên cứu trên chuột nhắt cho thấy khi tiếp xúc với PBDEs, vật thí nghiệm bị ảnh hưởng đối với hệ thần kinh, giảm cân, ảnh hưởng thận, tuyến giáp, và các rối loạn gan và da. Nghiên cứu trên động vật và con người đã chỉ ra rằng một số PBDEs có thể gây rối loạn hệ thống nội tiết và cũng có xu hướng tích tụ trong các mô mỡ của con người. Một nghiên cứu khác đã chỉ ra rằng octaBDE có thể là một nhân tố gây dị tật trên thai nhi [2], [3].

Nhiều nghiên cứu của các nhà khoa học trên thế giới đã chỉ ra sự có mặt của đồng loại
PBDEs chỉ thị trong trầm tích. Nghiên cứu của Moon và cộng sự (2007) về hàm lượng của 20 đồng loại PBDEs trong trầm tích tại một số vịnh và vùng ven biển Hàn Quốc cũng cho thấy sự tích lũy PBDEs khá cao, đặc biệt BDE-209 với khoảng dao động từ 0,03 đến $6,87 \mathrm{ng} / \mathrm{g}$ (dry wt) đối với tổng PBDEs (không tính BDE-209) và từ 2,0 đến $2253 \mathrm{ng} / \mathrm{g}$ (dry wt) đối với $\mathrm{BDE}$ 209. Nhóm nghiên cứu cũng đã chỉ ra sự tích lũy PBDEs trong trầm tích tại một số vịnh phát triển công nghiệp cao hơn hẳn so với các vùng ven biển khác [4].

PBDEs mới được quan tâm nghiên cứu tại Việt Nam trong khoảng 10 năm trở lại đây. Ở một số kênh rạch, ao hồ tại các khu tập trung, phân loại chất thải điện tử, hàm lượng PBDEs trong trầm tích dao động trong khoảng từ không phát hiện được đến $351.621 \mathrm{ng} / \mathrm{g}$ [5],[6], trong mẫu bụi trong nhà là từ 130 đến $12.000 \mathrm{ng} / \mathrm{g}$ và trong không khí là từ 620 đến 720 pg/m $\mathrm{m}^{3}$ [5][7].

Mục tiêu của nghiên cứu này là đánh giá mức độ tích lũy của PBDEs trong trầm tích bùn và một số động vật nhuyễn thể được lấy tại các ao, sông tại khu vực làng nghề tái chế nhựa Minh Khai, thị trấn Như Quỳnh, tỉnh Hưng Yên.

\section{Phương pháp nghiên cứu}

\subsection{Hóa chất và thiết bị}

Các chất chuẩn được sử dụng trong nghiên cứu là các chuẩn thường của $\mathrm{PBDEs}$ là hồn hợp của 8 đồng loại chỉ thị BDE-28, BDE-47, BDE99, BDE-100, BDE-153, BDE-154, BDE-183, $\mathrm{BDE}-209$, chuẩn đánh dấu đồng vị $\mathrm{PBDEs}$ và dung dịch nội chuẩn (PCB-52L và $\mathrm{PCB}-138 \mathrm{~L}$ ) với nồng độ gốc và mã số theo tiêu chuẩn tham chiếu US-EPA 1614. Các dung môi, vật liệu làm sạch như Diclomethan (DCM), axeton, nhexan, Silicagel, axit sunfuric đều là các hóa chất tinh khiết phân tích của Merk-Đức và Sharlau - Tây Ban Nha.

Thiết bị sử dụng cho phân tích định lượng các PBDEs là sắc ký khí ghép nối khối phổ GC/MS Perkin Elmer Clarus 680 GC-SQ8 MS. 


\subsection{Lấy mẫu}

Mẫu trầm tích mặt: Từ kết quả khảo sát thực tế tại địa phương, các vị trí lấy mẫu được lựa chọn cách vị trí các cống thải của cơ sở sản xuất ít nhất $2 \mathrm{~m}$. Mẫu trầm tích (bùn) được lấy bằng cuốc bùn chuyên dụng Peterson ở 10 vị trí khác nhau thuộc các ao hồ trong Làng Minh Khai, thị trấn Như Quỳnh, tỉnh Hưng Yên và tại con sông nhỏ chảy qua làng. Sau khi lấy mẫu, mỗi mẫu được trộn đều trong khay inox và cho vào lọ thủy tinh tối màu, bảo quản lạnh để vận chuyển về phòng thí nghiệm. Quá trình vận chuyển và bảo quản theo TCVN 6663-15:2004 (ISO 5667-15:1999)

Tại phòng thí nghiệm, mẫu bùn được hong khô tự nhiên trong phòng tối, sau đó mẫu được nghiền đến cỡ hạt $0,63 \mu \mathrm{m}$ và bảo quản trong tủ lạnh $-4^{\circ} \div-2^{\circ} \mathrm{C}$ để chờ phân tích.
Mẫu sinh học: Qua nghiên cứu thực địa, tại khu vực nghiên cứu có hai loài nhuyền thể sinh sống là trai sông (Anodonta cygnea) và ốc bươu vàng (Pomacea canaliculata). Do vậy, tiến hành thu bắt hai loại nhuyễn thể này tại xung quanh các vị trí lấy mẫu trầm tích khoảng 5$10 \mathrm{~m}$ với các kích cỡ khác nhau được mô tả trong Bảng 1. Mẫu sinh học được bảo quản đông lạnh và vận chuyển về phòng thí nghiệm.

Tại phòng thí nghiệm, trai và ốc bươu vàng được cân trọng lượng, đo kích thước để phân loại. Sau khi phân loại, các nhóm mẫu được tách bỏ vỏ, lấy phần mô thịt để tiến hành đồng hóa mẫu. Mẫu sinh học đã đồng hóa được bảo quản đông lạnh và tiến hành chiết mẫu trong khoảng thời gian 1 tháng.

Bảng 1 . Thông tin lấy mẫu trầm tích và sinh học

\begin{tabular}{|c|c|c|c|c|c|}
\hline STT & $\begin{array}{l}\text { Mẫu } \\
\text { trầm } \\
\text { tích }\end{array}$ & Mẫu sinh học & Vĩ độ & Kinh độ & Ghi chú \\
\hline 1 & MK1 & OBV1.1; OBV1.2 & $20^{\circ} 59^{\prime} 39,6^{\prime \prime}$ & $105^{\circ} 59^{\prime} 07,5^{\prime \prime}$ & \multirow{10}{*}{ 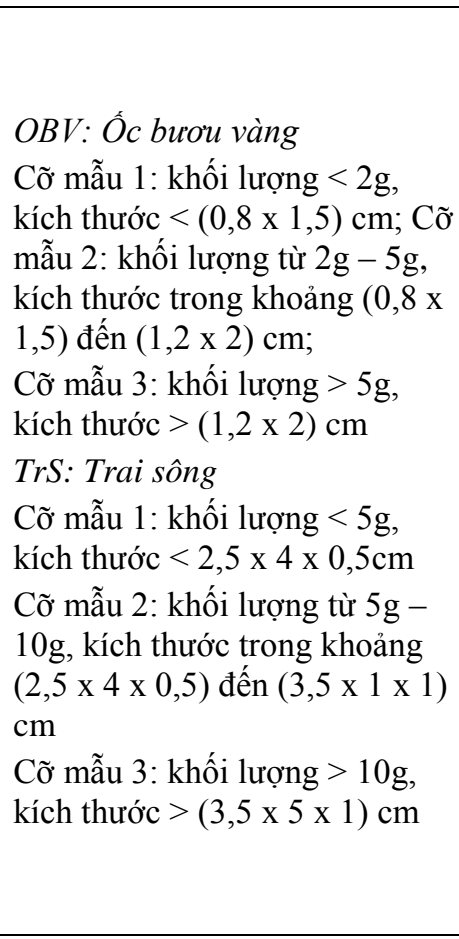 } \\
\hline 2 & MK2 & OBV2.1; OBV2.2 & $20^{\circ} 59^{\prime} 37,9^{\prime \prime}$ & $105^{\circ} 59^{\prime} 06,4^{\prime \prime}$ & \\
\hline 3 & MK3 & OBV3.1; OBV3.2 & $20^{\circ} 59^{\prime} 34,0^{\prime \prime}$ & $105^{\circ} 59^{\prime} 08,8^{\prime \prime}$ & \\
\hline 4 & MK4 & $\begin{array}{l}\text { OBV4.1;OBV4.3 } \\
\operatorname{TrS} 4.1 ; \operatorname{TrS} 4.2 ; \operatorname{TrS} 4.3\end{array}$ & $20^{\circ} 59^{\prime} 31,1$ ', & $105^{\circ} 59^{\prime} 14,4^{\prime \prime}$ & \\
\hline 5 & MK5 & $\begin{array}{l}\text { OBV5.2; OBV5.3 } \\
\text { TrS5.1; TrS5.2 }\end{array}$ & $20^{\circ} 59^{\prime} 31,6^{\prime \prime}$ & $105^{\circ} 59^{\prime} 10,7^{\prime}$ & \\
\hline 6 & MK6 & $\begin{array}{l}\text { OBV6.1; OBV6.2; } \\
\text { OBV6.3 }\end{array}$ & $20^{\circ} 59^{\prime} 39,6^{\prime \prime}$ & $105^{\circ} 58^{\prime} 48,9^{\prime \prime}$ & \\
\hline 7 & MK7 & $\begin{array}{l}\text { OBV7.1; OBV7.2; } \\
\text { OBV7.3 }\end{array}$ & $20^{\circ} 59^{\prime} 23,7^{\prime \prime}$ & $105^{\circ} 58^{\prime} 45,3^{\prime \prime}$ & \\
\hline 8 & MK8 & $\begin{array}{l}\text { OBV8.1; OBV8.2; } \\
\text { OBV8.3 } \\
\text { TrS8.1; TrS8.2; TrS8.3 }\end{array}$ & $21^{\circ} 00^{\prime} 02,5^{\prime \prime}$ & $105^{\circ} 58^{\prime} 54,4^{\prime \prime}$ & \\
\hline 9 & MK9 & $\begin{array}{l}\text { OBV9.1; OBV9.2; } \\
\text { OBV9.3 } \\
\text { TrS9.1; TrS9.2; TrS9.3 }\end{array}$ & $21^{\circ} 00^{\prime} 23,3^{\prime \prime}$ & $105^{\circ} 58^{\prime} 59,6^{\prime \prime}$ & \\
\hline 10 & MK10 & $\begin{array}{l}\text { OBV10.1; OBV10.2; } \\
\text { OBV10.3 }\end{array}$ & $20^{\circ} 59^{\prime} 35,4^{\prime \prime}$ & $105^{\circ} 59^{\prime} 04,9^{\prime \prime}$ & \\
\hline
\end{tabular}




\subsection{Xư lý và phân tích mẫu}

Quy trình xử lý mẫu trầm tích, sinh học và phân tích định lượng xác định PBDEs trong mẫu được tham khảo theo tiêu chuẩn US-EPA 1614 [8]. Quy trình được nghiên cứu và đánh giá độ tin cậy tại Phòng thí nghiệm trước khi áp dụng để phân tích mẫu thông qua độ lặp lại và độ thu hồi của kết quả phân tích.

\section{Xư lý mẫu}

Kỹ thuật chiết mẫu được sử dụng trong nghiên cứu là kỹ thuật chiết Soxhlet với hỗn hợp dung môi axeton:n-hexan (1:1) trong thời gian 16 giờ. Dịch chiết sau đó được cô về $10 \mathrm{ml}$ và tiến hành rửa axit và rửa nước để loại bỏ các chất màu hữu cơ và lipit (đối với mẫu sinh học). Tiếp tục quá trình làm sạch mẫu bằng cách cho dịch chiết qua cột Silicagel đa lớp và Silicagel axit đơn lớp. Trong cả hai quá trình làm sạch, các đồng loại PBDEs được rửa giải bằng hỗn hợp dung môi DCM:n-hexan (5:95). Cuối cùng, dung dịch rửa giải được cô về $200 \mu 1$, thêm chất nội chuẩn là $\mathrm{PCB}-52 \mathrm{~L}$ và $\mathrm{PCB} 138 \mathrm{~L}$.

\section{Định luợng PBDEs}

Các đồng loại PBDEs được định lượng bằng phương pháp nội chuẩn với chất nội chuẩn là $\mathrm{PCB}-52 \mathrm{~L}$ và $\mathrm{PCB}-138 \mathrm{~L}$ trên thiết bị sắc ký khí ghép nối khối phổ GC/MS Perkin Elmer Clarus 680 GC-SQ8 MS, cột tách chuyên dụng cho tách và định lượng PBDEs là cột Restex 1614, pha tĩnh Poly (5\% diphenyl, 95\% dimethyl siloxan), kích thước $15 \mathrm{~m} \times 0,25 \mathrm{~mm} \times$ $0,10 \mu \mathrm{m}$.

Bên cạnh đó, hỗn hợp chuẩn đánh dấu đồng vị gồm 8 đồng loại PBDEs như chuẩn thường được sử dụng làm chất đồng hành trong quá trình xử lý mẫu và phân tích nhằm đánh giá độ thu hồi của phương pháp phân tích. Độ thu hồi của các chuẩn đánh dấu đồng vị thu được biến thiên từ 62,1 đến $146,6 \%$, thỏa mãn về độ thu hồi trên nền mẫu rắn tham chiếu từ tiêu chuẩn US-EPD 1614. Giới hạn phát hiện của phương pháp phân tích $\mathrm{PBDEs}$ trong trầm tích và mẫu sinh học thấp nhất đối với BDE-153 là $0,175 \mathrm{ng} / \mathrm{g}$ và $\mathrm{MQL}$ cao nhất là 2,901 ng/g đối với BDE-100.

\section{4. Đánh giá mức độ tích lũy}

Hàm lượng các đồng loại PBDEs trong mẫu trầm tích được biểu diễn bằng đơn vị ng/g trọng lượng khô và trong mẫu sinh học được biểu diễ்n bằng $\mathrm{ng} / \mathrm{g}$ trọng lượng ướt của mô thịt. Ngoài ra, hệ số tích lũy sinh học trầm tích (BSAF) được sử dụng để đánh giá mức độ tích lũy PBDEs trong mẫu nhuyễn thể được tính theo công thức sau [9][10]:

$$
\text { BSAF }=\frac{C_{0} / f_{l}}{C_{s} / f_{\text {Soc }}}
$$

Trong đó:

- $\mathrm{C}_{\mathrm{o}}$ là hàm lượng của PBDEs trong cơ thể sống (ng/g wet wt);

- $\mathrm{f}_{1}$ là tỷ lệ lipit trong cơ thể sống ( $\mathrm{g}$ lipit/g wet wt);

- $\mathrm{C}_{\mathrm{s}}$ là hàm lượng của PBDEstrong trầm tích mặt (ng/g dry wt);

- $\mathrm{f}_{\mathrm{soc}}$ là hệ số cacbon hữu cơ trong trầm tích (gOC/g dry wt)

Ngoài ra, nghiên cứu sử dụng phần mềm thống kê SPSS (Statistical Product and Service Solutions) để đánh giá mối tương quan giữa hàm lượng $\mathrm{PBDEs}$ trong trầm tích và trong sinh vật bằng hàm phân tích tương quan Pearson.

\section{Kết quả và thảo luận}

\subsection{Hàm lương PBDEs trong mẫu}

\subsubsection{Hàm luợng PBDEs trong trầm tích}

Trong trầm tích tại làng nghề tái chế nhựa Minh Khai, thị trấn Như Quỳnh, tỉnh Hưng Yên, hàm lượng các đồng loại PBDEs khá cao so với các nghiên cứu trong nước. Hàm lượng các PBDEs trong mẫu trầm tích dao động từ 6,03 đến $159 \mathrm{ng} / \mathrm{g}$ trọng lượng khô (dry wt), trong khi đó PBDEs trong trầm tích sông nội đô Hà Nội dao động từ 0,03 đến $17,5 \mathrm{ng} / \mathrm{g}$ (dry wt) [5]; tại các hồ ở Hà Nội $(0,035$ đến $0,26 \mathrm{ng} / \mathrm{g}$ dry wt) [6], tại các cống rãnh nội thành Thành phố Hồ Chí Minh (1,5 đến $11 \mathrm{ng} / \mathrm{g}$ dry wt), các cống rãnh ngoại thành Thành phố Hồ Chí Minh 
$(\mathrm{KPH}-1,5 \mathrm{ng} / \mathrm{g}$ dry wt, cửa sông Sài Gòn Đồng Nai (KPH - 0,065 ng/g dry wt) [11].

Hàm lượng PBDEs trong các mẫu bùn MK06 đến MK10 khá cao so với các điểm còn lại. Các điểm lấy mẫu này là nơi tiếp nhận nước thải từ quá trình sản xuất hạt nhựa và các hộp nhựa dùng một lần tại làng nghề. Các vị trí MK02 đến MK05 là các điểm thuộc ao làng tiếp nhận nước thải riêng lẻ từ các hộ gia đình có hoạt động tái chế nhựa. Kết quả khảo sát khu vực nghiên cứu cũng cho thấy mức độ ô nhiễm môi trường tại làng nghề là rất nghiêm trọng. Tại các ao hồ, sông tại khu vực, nước có màu đen và mùi khó chịu. Ngoài ra, hàm lượng Cacbon hữu cơ trong các mẫu bùn tại các vị trí lấy mẫu cũng khá cao, dao động từ 5,42 đến $21,6 \%$.

Xét về tỷ lệ đóng góp của các đồng loại, tỷ lệ các đồng loại BDE-47, BDE-99, BDE-100 chiếm tới $62,4 \%$ tổng hàm lượng PBDEs (Hình 1). Kết quả này tương đồng với thông tin được cung cấp tại "Hướng dẫn kỹ thuật kiểm kê phát thải và bảo vệ môi trường đối với hoạt động sản xuất công nghiệp có sử dụng các chất ô nhiễm hữu cơ khó phân hủy" - Tổng cục Môi trường (2014), thành phần của BDE47 chiếm $32 \%$, BDE99 và $\mathrm{BDE} 100$ chiếm $56 \%$ trong tổng các đồng loại của C-PentaBDE (gồm BDE-17,
BDE-28, BDE-47, BDE-99, BDE-100, BDE153, BDE-154, BDE-183) [12].

\section{Hàm lương PBDEs trong mẫu sinh học}

Kết quả hàm lượng các đồng loại PBDEs trong mâ̂u ốc bươu vàng và trai sông được thể hiện trong Bảng 2.

Kết quả Bảng 2 cho thấy, các đồng loại PBDEs được phát hiện thấy ở tất cả các mầu sinh học. Tuy nhiên, tổng hàm lượng PBDEs trong ốc bươu vàng dao động từ 10,2 đến 129 $\mathrm{ng} / \mathrm{g}$ (wet $\mathrm{wt}$ ); trong trai sông từ 11,6 đến 79,6 $\mathrm{ng} / \mathrm{g}$ (wet wt).

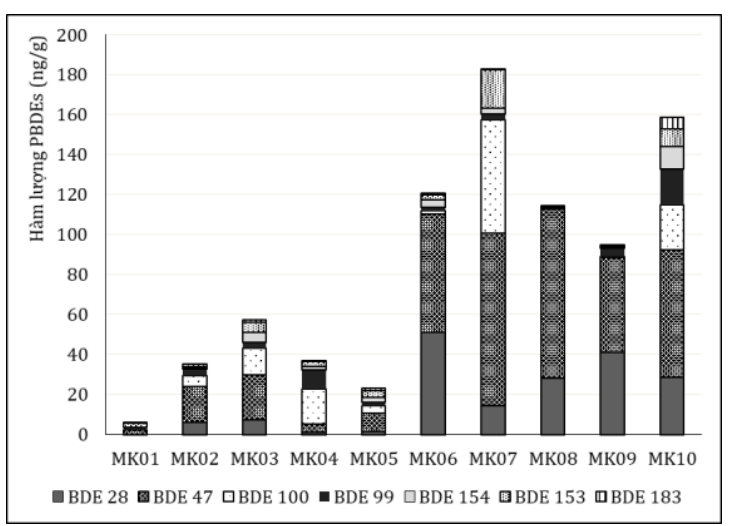

Hình 1. Hàm lượng PBDEs trong mẫu trầm tích bùn.

Bảng 2. Hàm lượng tổng PBDEs trong mẫu sinh học

\begin{tabular}{lllllllll}
\hline STT & Ký hiệu mẫu & $\begin{array}{l}\text { PBDEs } \\
(\mathrm{ng} / \mathrm{g} \text { wet } \\
\text { wt) }\end{array}$ & STT & $\begin{array}{l}\text { Ký hiệu } \\
\text { mâ̂u }\end{array}$ & $\begin{array}{l}\text { PBDEs } \\
(\mathrm{ng} / \mathrm{g} \text { wet } \\
\text { wt })\end{array}$ & STT & Ký hiệu mẫu & $\begin{array}{l}\text { PBDEs } \\
\text { (ng/g wet } \\
\text { wt) }\end{array}$ \\
\hline 1 & OBV 1-1 & 10,2 & 13 & OBV 6-2 & 51,5 & 25 & OBV 10-3 & 129 \\
2 & OBV 1-2 & 12,3 & 14 & OBV 7-1 & 36,7 & 26 & TrS 4-1 & 11,6 \\
3 & OBV 2-1 & 23,4 & 15 & OBV 7-2 & 56,2 & 27 & TrS 4-2 & 40,6 \\
4 & OBV 2-2 & 33,5 & 16 & OBV 7-3 & 121 & 28 & TrS 4-3 & 61,1 \\
5 & OBV 3-1 & 34,3 & 17 & OBV 8-1 & 32,0 & 29 & TrS5.1 & 18,0 \\
6 & OBV 3-2 & 40,3 & 18 & OBV 8-2 & 79,3 & 30 & TrS5.2 & 38,4 \\
7 & OBV 4-1 & 27,6 & 19 & OBV 8-3 & 90,7 & 31 & TrS8.1 & 31,6 \\
8 & OBV 4-2 & 45,9 & 20 & OBV 9-1 & 33,2 & 32 & TrS8.2 & 35,7 \\
9 & OBV 4-3 & 63,2 & 21 & OBV 9-2 & 47,9 & 33 & TrS8.3 & 60,1 \\
10 & OBV 5-2 & 29,0 & 22 & OBV 9-3 & 55,6 & 34 & TrS9.1 & 35,5 \\
11 & OBV 5-3 & 40,5 & 23 & OBV 10-1 & 91,7 & 35 & TrS9.2 & 36,5 \\
12 & OBV 6-1 & 38,7 & 24 & OBV 10-2 & 118 & 36 & TrS9.3 & 79,6 \\
\hline
\end{tabular}


Trong các điểm lấy mẫu, hàm lượng PBDEs trung bình trong mẫu ốc bươ vàng tại vị trí MK10 có giá trị cao nhất.

Vị trí MK10 là một ao chứa nhân tạo tiếp nhận nước thải của các hộ sản xuât xung quanh, thời điểm lấy mẫu ao ở dạng sinh lầy, có rau khoai, rau muống mọc hoang và bên cạnh bớ là bãi rác tập kết phế thải tự phát của người dân.

Nghiên cứu này chưa xác định được độ tuổi của các sinh vật nghiên cứu, nhưng theo kết quả phân loại dựa vào kịch cớ và kết quả phân tích cho thấy về xu hướng chung mức độ tích lũy PBDEs trong các động vật nhuyễn thể có kích thước lớn cao hơn so với các loại có kích thước bé. Sự tích lũy PBDEs trong ốc bươu vàng cao hơn trai sông có thể được giải thích do đặc tính hô hấp và trao đổi chất của trai và ốc. Sự trao đổi chất của trai sông được lọc qua mang, còn ốc bươu vàng có đặc tính ăn tạp với sự hấp thụ trực tiếp các chất ô nhiễm từ bùn đáy, chất thải phát tán trong môi trường nước và trầm tích bùn.

Hàm lượng PBDEs trong ốc và trai của nghiên cứu này cao hơn rất nhiều so với hàm lượng trong vẹm tại vùng ven biển Trung Quốc (tổng của 13 đồng loại PBDEs trừ BDE-209 là $0,68 \div 2,43 \mathrm{ng} / \mathrm{g}$ dry wt) [10]; trong động vật nhuyễn thể hai mảnh vỏ tại ven biển Hàn Quốc (trung bình là $2,94 \mathrm{ng} / \mathrm{g}$ wet $\mathrm{wt}$ ) [13] và gần bằng với hàm lượng tồng 15 đồng loại PBDEs trong vẹm xanh ở vùng biển Hồng Kong $(27,0$

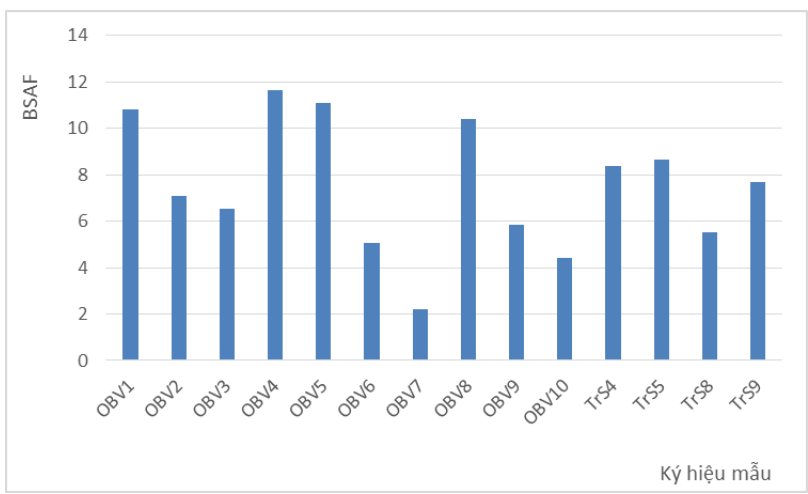

Hình 2. BSAF trung bình của các mẫu sinh học tại các điểm lấy mẫu. $\div 83,7$ dry wt) [10]. Sự tích lũy PBDEs trong trầm tích, sinh vật có nguồn gốc từ các nguồn thải nước, khí, chất thải rắn. Từ các số liệu này có thể khẳng định hoạt động sản xuất của làng nghề Minh Khai có phát thải PBDEs vào môi trường và đã có sự tích lũy trong sinh vật đáy ở khu vực này. Điều đó cũng đồng thời đưa đến những cảnh báo về ảnh hưởng của môi trường làng nghề đến hệ sinh thải và sức khỏe của cộng đồng dân cư sinh sống tại làng nghề.

\section{2. Đánh giá mức độ tích lũy sinh học}

Trong nghiên cứu này, hệ số tương quan Pearson và phần mềm SPSS được sử dụng để đánh giá mối tương quan giữa hàm lượng PBDEs trong mẫu trầm tích và trong mô thịt của sinh vật (ốc bươu vàng, trai sông). Hệ số tương quan Pearson chỉ ra mối tương quan có ý nghĩa thống kê đo lường cho hai biến số là hàm lượng $\mathrm{PBDEs}$ trong trầm tích và trong sinh vật. Giá trị hệ số tương quan Pearson thu được là: $0,6<\mathrm{r}=0,644<0,8$ điều đó chứng tỏ hàm lượng PBDEs tích lũy trong ốc bươu vàng và trai sông có mối tương quan mạnh với hàm lượng $\mathrm{PBDEs}$ trong trầm tích nơi chúng sinh sống.

Kết quả tính toán hệ số tích lũy sinh học trầm tích của ốc bươu vàng và trai sông tại khu vực nghiên cứu được thể hiện trong biểu đồ Hình 2.

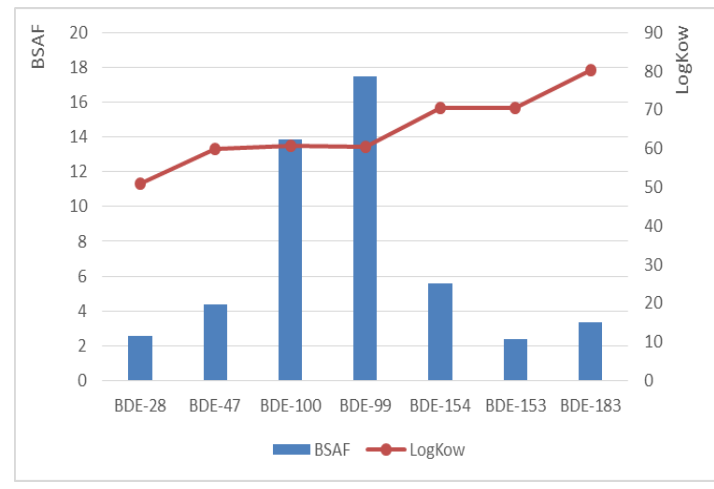

Hình 3. Mối tương quan giữa BSAF và $\operatorname{logKow}$. 
Hệ số BSAF tính toán được của ốc bươu vàng và trai sông dao động từ 2,19 đến 11,6 chứng tỏ sự khả năng tích lũy sinh học của PBDEs trong các loài nhuyễn thể là khá cao. Điều này cho thấy nguy cơ tích lũy sinh học của PBDEs trong chuỗi thức ăn và nguy cơ ảnh hưởng đến sức khỏe con người.

Bên cạnh đó, sự tích lũy sinh học trầm tích (BSAF) cao hơn với các đồng loại PBDE có hệ số octanol - nước thấp (logKow) chỉ ra rằng các đồng loại có Kow cao có khả năng được giữ lại trong trầm tích tốt hơn (Hình 3 ). Điều này có thể được giải thích do ái lực cao của các hợp chất này đối với các chất hấp thụ hữu cơ trong trầm tích và sự cản trở của các chất hữu cơ cao phân tử kỵ nước thâm nhập trong màng tế bào [9].

\section{Kết luận}

Kết quả nghiên cứu về mức độ tích lũy PBDEs trong trầm tích và mẫu nhuyễn thể tại làng nghề tái chế nhựa Minh Khai, thị trấn Như Quỳnh, huyện Văn Lâm, tỉnh Hưng Yên cho thấy nguy cơ ô nhiễm các hợp chất hữu cơ gây ô nhiễm môi trường tại khu vực là rất lớn. Hàm lượng tổng PBDEs trong cả mẫu trầm tích và mầu sinh học đều khá cao với giá trị hàm lượng tổng PBDEs cao nhất tương ứng là $183 \mathrm{ng} / \mathrm{g}$ (dry wt) và 129 ng/g (wet wt). Mặt khác, hệ số tương quan Pearson cho thấy mối tương quan cao giữa hàm lượng PBDEs trong trầm tích và trong mô thịt của hai loài nhuyễn thể sinh sống tại khu vực. Đồng thời, hệ số tích lũy sinh học trầm tích (BSAF) cao (lớn nhất là 11,6) cho thấy nguy cơ tích lũy sinh học của PBDEs trong động vật đáy tại khu vực là tương đối lớn.

Kết quả nghiên cứu này là cơ cở khoa học ban đầu cho các nhà quản lý thúc đẩy triển khai các hoạt động kiểm kê và kiểm soát phát thải PBDEs trong môi trường. Vì vậy, cần có các nghiên cứu mở rộng theo không gian và thời gian về hàm lượng PBDEs trong các đối tượng môi trường như nước, không khí, đất, trầm tích và các sinh vật trong nước.

\section{Lời cảm ơn}

Nghiên cứu này được tài trợ bởi Bộ Tài nguyên và Môi trường, Đề tài mã số: 13.01.17.K.01.

\section{Tài liệu tham khảo}

[1] Nouira T., Risso C., Chouba L., Budzinski H., Boussetta H., (2013), Polychlorinated biphenyls (PCBs) and Polybrominated Diphenyl Ethers (PBDEs) in surface sediments from Monastir Bay (Tunisia, Central Mediterranean): occurrence, distribution and seasonal variations, Chemosphere 93(3), pp. 487-493.

[2] Amelie Kierkegaard (2007), PBDEs in the Environment, Doctor thesis, Department of Applied Environmental Science, Stockholm University. ISBN: 91-7155-410-6.

[3] US Department of Health and Human Services, Agency for Toxic Substances and Disease registry (ATSDR) (2015), Draft toxicological profile for Polybrominated diphenyl ethers (PBDEs), Public Health Service, Atlanta, GA.

[4] Moon, H.-B., Kannan, K., Choi, M., Choi, H.-G., (2007), Polybrominated diphenylethers (PBDEs) in marine sediments from industrialized bays of Korea, Marine Pollution Bulletin, 54, pp. 14021412.

[5] Hoang Quoc Anh, Vu Duc Nam, Tran Manh Tri, Nguyen Manh Ha, Nguyen Thuy Ngoc, Pham Thi Ngoc Mai, Duong Hong Anh, Nguyen Hung Minh, Nguyen Anh Tuan, Tu Binh Minh (2016), Polybrominated diphenyl ethers in plastic products, indoor dust, sediment and fish from informal e-waste recycling sites in Vietnam: a comprehensive assessment of contamination, accumulation pattern, emissions, and human exposure, Environ Geochem Health 39(4), pp. 935-954.

[6] Pham Thi Ngoc Mai, Nguyen Van Thuong, Trinh Thi Tham, Nguyen Khanh Hoang, Hoang Quoc Anh, Tran Manh Tri, Le Si Hung, Dao Thi Nhung (2015), Distribution, accumulation profile, and risk assessment of polybrominateddiphenyl ether in sediment from lake and river systems in Hanoi Metropolitan Area, Vietnam, Environmental Science and Pollution Research, pp. 1-10

[7] Tổng cục môi trường (2014), Kiểm kê phát thải và bảo vệ môi trường đối với hoạt động sản xuất công nghiệp có sử dụng các chất ô nhiễm hữu cơ khó phân hủy. 
[8] U.S. Environmental Protection Agency (2007), Method 1614: Brominated Diphenyl Ethers in Water Soil, Sediment and Tissue by HRGC/HRMS.

[9] Ying Liu, Gene J.Zheng, Hongxia Yu, Michael Martin, Bruce J.Richardson, Michael H.W. Lam, Paul K.S. Lam (2005), Polybrominated diphenyl ethers (PBDEs) in sediments and mussel tissues from Hong Kong marine waters, Marine Pollution Bulletin 50 (11), pp. 1173-1184.

[10] Zhen Wang, Xindong Ma, Zhongsheng Lin, Guangshui Na, Ziwei Yao (2009), Congener specific distributions of polybrominated diphenyl ethers (PBDEs) in sediment and mussel (Mytilus edulis) of the Bo Sea, China, Chemosphere 74(7), pp. 896-901.

[11] Tu Binh Minh, Hisato Iwta, Shin Takahashi, Pham Hung Viet, Bui Cach Tuyen, and Shinsuke
Tanabe (2008), Persistent Organic Pollutants in Vietnam: Environmental contamination and human exposure, Rev Environmenal Contamination Toxicology, Springer, pp. 213-285

[12] Tran Manh Tri, Hoang Quoc Anh, Trinh Thi Tham, Tran Van Quy, Masafumi Nakamura, Masayo Nishida, Yasuaki Maeda, Luu Van Boi, Tu Binh Minh (2016), Distribution and Depth Profiles of Polychlorinated Dibenzo-p-Dioxins, Polychlorinated Dibenzofurans, and Polychlorinated Biphenyls in Sediment Collected from Offshore Waters of Central Vietnam, Marine Pollution Bulletin 106, pp. 341-346.

[13] Moon, H.-B., Kannan, K., Lee, S.J., Choi, M., (2007b), Polybrominated diphenyl ethers (PBDEs) in sediment and bivalves from Korean coastal waters, Chemosphere 66(2), pp. 243-251.

\title{
Assessment of the Distribution and Accumulation of Polybrominated Diphenyl Ethers in the Environment in the Plastic Recycling Village of Minh Khai, Nhu Quynh Town, Hung Yen Province
}

\author{
Trinh Thi Tham ${ }^{1}$, Nguyen Thi Huong ${ }^{2}$, Bui Thi Phuong ${ }^{1}$, Le Thi Trinh ${ }^{1}$ \\ ${ }^{1}$ Hanoi University of Natural Resources \& Environment, 41A Phu Dien, Bac Tu Liem, Hanoi, Vietnam \\ ${ }^{2}$ Hanoi University of Public Health, 1A Duc Thang, Dong Ngac, Bac Tu Liem, Hanoi, Vietnam
}

\begin{abstract}
This study assessed the accumulation of 07 polybrominated diphenyl ether (PBDEs) indicator congeners (BDE-28, BDE-47, BDE-100, BDE-99, BDE-154, BDE-153, BDE-183) in sediment, in tissue of the Anodonta cygnea and Pomacea canaliculata in the Minh Khai Plastic Recycling Village, Hung Yen Province. Samples were extracted by Soxhlet Extraction and quantified on GC/MS using internal standard calibration. The concentration of total PBDEs in the sediments and biota samples ranged from 6.03 to $183 \mathrm{ng} / \mathrm{g}$ in dry wt and 10.2 to $129 \mathrm{ng} / \mathrm{g}$ in wet wt, in respectively. The results showed that the accumulation of PBDEs in sludge sediments in this areas was rather high, and there was a positive correlation between PBDEs content in biological samples and sediment samples. The high values of BSAF demonstrated the high bioaccumulation potential of PBDEs in biota. This is the scientific basis for the assessment of ecological and environmental risks of PBDEs pollution in the village environment.
\end{abstract}

Keywords: PBDEs, BSAF, sediment, accumulation. 